\title{
A Study on Morbidity Profile among Elderly Population in Visakhapatnam District, Andhra Pradesh.
}

\author{
Srinivas P.J. ${ }^{1}$, Manjubhashini $\mathrm{S}^{2}$. \\ 1. Assistant Professor, Department of Community Medicine, Andhra Medical College, Vishakhapatnam, Andhra \\ Pradesh, India. \\ 2. Assistant Professor, Department of Community Medicine, Katuri Medical College and Hospital, Guntur, \\ Andhra Pradesh, India
}

\begin{abstract}
:
Background: The elderly are one of the most vulnerable and high risk groups in terms of health and their health seeking behavior is crucial in any society.

Objectives: The study aims to assess the morbidity profile among the elderly population aged 60 years and above.

Material and Methods: A community based cross-sectional study was done in Visakhapatnam district. Rural \& urban areas were selected by means of simple random sampling. 17,415 population was screened from 3,383 households in both rural and urban areas to identify 1200 elderly aged 60 and above were examined clinically with pretested questionnaire.

Results: Among the elderly population aged 60 years and above, 64\% have morbidity. Diseases of Musculoskeletal System (39\%) followed by diseases of Circulatory system (21\%) and diseases of Eye and adnexa (20\%) were most commonly seen among study population. Joint pains (41\%), defective vision (34\%), polyuria (12\%) and defective hearing (7\%) were most common presenting complaints. The most common history of previous illness was hypertension (12\%) and diabetes mellitus (6\%) in both rural and urban areas. $40 \%$ of elderly individuals presented with Anemia. 25\% of the study population has more than one disease.

Conclusion: The prevalence of morbidity among elderly aged 60 years and above was 64\%. 25\% of the study population has more than one disease. Hence special clinics for elderly need to be organized and integrated services should be provided.
\end{abstract}

Key-Words: Elderly, Morbidity profile, Rural areas, Urban areas.

\section{Introduction}

Ageing is a natural process; always associated with physiological and biological decline. It is the outcome of certain structural and functional changes takes place in the major parts of the body as the life years increases. In the words of Seneca; "Old age is an incurable disease". As Sir James Sterling Ross said "You do not heal old age, you protect it, you promote it and you extend it". These are in fact the basic principles of Preventive Medicine. The ageing population is growing at an unprecedented rate. World population ageing is enduring; the proportion of older persons has been rising steadily, from 7 per cent in 1950 to 11 per cent in 2007, with an expected rise to reach 22 percent in 2050. [1] There are presently 740 million individuals in the world aged 60 years or over, and that number is expected to rise to 1 billion by the end of the present decade and possibly to 2 billion by mid-century. [2] India alone has around 100 million elderly at present, and the number is expected to increase to 323 million, constituting 20 per cent of the total population, by 2050. [3] The Indian aged population is currently the second largest in the world. According to the 2001 census $7.7 \%$ of total population were above the age of 60 years and estimated to double i.e. $12.30 \%$ by 2025 [4].

In ordinary social intercourse a person would be considered old when his children were married and he had grand children regardless of his chronological age. In academic research, retirement age is often taken as index of aged status - chronological age of 58 or 60 is considered as the beginning of old age. [4] Longevity has increased significantly in the last few decades mainly due to the socio-economic and health care developments. These factors are responsible for the higher numerical presence of elderly people leading to change in age structure, and a higher dependency ratio. Ageing is generally a process of deterioration in the functional capacity of an individual that results from structural changes, with advancement of age. It is not merely a matter of accumulating years but also a process of "adding life to years, not years to life." The world health day theme in 2012 was "Good health adds life to years". The focus was how good health throughout life can help older men and women lead full and productive lives and are a resource for their families and communities. [5] Due to structural and functional changes in the major parts of the body as the life years increases they are affected by chronic diseases which are more frequent among older people than the younger people. The main causes of 
illness are arthritis, cataract, bronchitis, avitaminosis, ear diseases, hypertension, diabetes, rheumatism, helminthic infestations, accidents etc The findings of an ICMR survey conducted in 1984-85 of elderly persons over $60 \mathrm{yrs}$ of age attending geriatric clinics in rural areas presented the following findings. The percentage of elderly reporting various ailments were visual impairment $88.0 \%$, Locomotive disorders, joints, muscles $40.0 \%$, Neurological complaints $18.7 \%$, Cardiovascular diseases $17.4 \%$, Respiratory diseases $16.1 \%$, Skin conditions 13.3\%, Gastro-intestinal/abdominal disorder 9.0\%, Psychiatric problem 8.5\%, Hearing loss $8.2 \%$ and Genitourinary disorder 3.5\% . [6]. With this background the aim of the study was to assess the morbidity profile among the Elderly aged 60yrs and above in Visakhapatnam district, Andhra Pradesh.

\section{Materials And Methods}

2.1 Sampling frame: The study was conducted in the urban and rural areas of Visakhapatnam district, Andhra Pradesh. 2.2 Sampling Procedure: Urban and Rural areas were listed alphabetically and selected randomly using random numbers table to conduct the study. Urban areas include Simhagiri colony, Indira colony, Yatapalem, Nerellakoneru and Chaluvathota. Rural areas include Mogalipuram, Mallunaidupalem, Shivashaktinagar, Bottuvanipalem and Swathantranagar.2.3 Study Population: All individuals aged 60 years and above were included in the study. 2.4Sample size: All individuals aged 60 years and above of the selected urban and rural areas were included in the study. 1200 elderly aged 60 and above were examined from 17,415 population residing in 3,383 households in both rural and urban areas. 2.5 Study design: A cross- sectional descriptive study.2.6 Collection of data: All the subjects were personally contacted at their homes, interviewed and examined using the pre tested questionnaire. It included 2.7 Socio demographic factors: Age, Sex, Religion, Social status, Marital status, Education, Occupation (present and past), type of family, Family income, No. of members of the family.2.8 Clinical examination: Complaints, Past History, Family history, Personal history, diet, Smoking, Alcohol, General Condition on examination, Vital data, Systemic examination and Diagnosis. After examination Diagnoses was classified according to International Classification of Diseases [7] 2.9 Data Analysis: Data was entered in Microsoft Excel and analyzed using Epi info Software. Appropriate tests of significance were used wherever necessary. Suitable diagrams were also drawn for representing the data. Vancouver style was used in writing Bibliography.

\section{Results}

The present study was conducted in the urban and rural areas of Visakhapatnam district, Andhra Pradesh. A total of 17,415 population was screened from 3,383 households in both rural and urban areas to identify 1,200 elderly people i.e. 6.8\%. 600 elderly persons were identified in rural areas after surveying 8,308 people living in 1,574 households. Similarly, another 600 elderly were identified in urban areas after surveying 9,107 people living in 1,809 households. The percentage of elderly in the rural areas was $7.2 \%$. In the urban areas it was $6.6 \%$. The percentage of elderly individuals in our study area ranged from $6.2 \%$ to $8.8 \%$ with an average of $6.8 \%$. Among the study population $44 \%$ (527) were in the age group $60-64$ years. $60 \%$ of the study population were females and $40 \%$ were males. Majority of the study population $75.75 \%$ were illiterates, $42 \%$ were singles, $72 \%$ of the study population had some form of social support, $22.5 \%$ were employed, $(63 \%)$ belong to class $\mathrm{V}$ and $98.9 \%$ of the study population take mixed diet. Only $1.1 \%$ of the study population were Vegetarians.

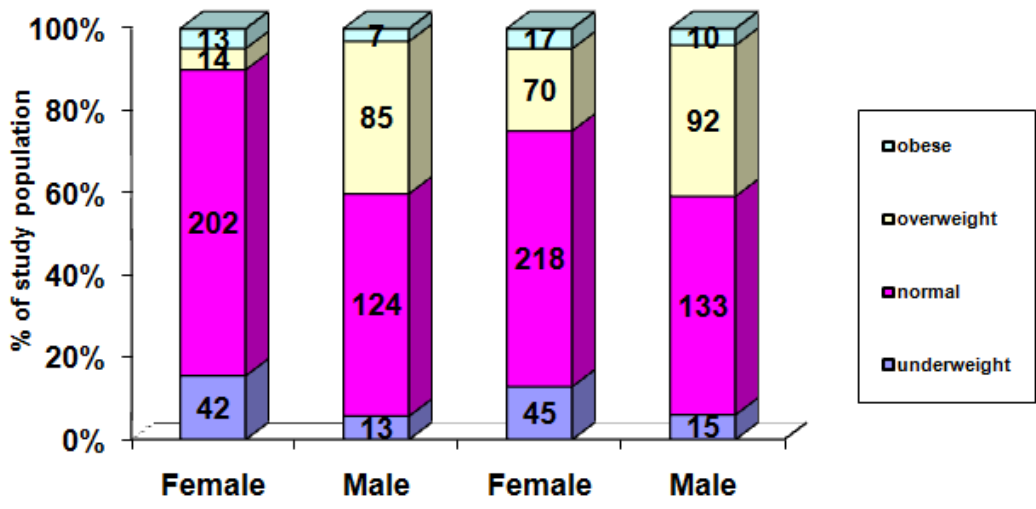

\section{Rural Urban}

Figure 1 Distribution of study population according to Gender and Body Mass Index 
The distribution of study population according to Gender and Body Mass Index is shown in Figure 1. $9.6 \%$ had chronic energy deficiency. $34 \%$ of the study population were overweight and obese. More than half of the study population had normal body mass index. There was no rural and urban difference. Among the underweight category more number of females were underweight as compared to males in both rural and urban areas. In the overweight category males were more in number as compared to females in both rural and urban areas.

In our study $36.6 \%$ of the study population was smokers. $38.5 \%$ in rural areas and $34.7 \%$ in urban areas were smokers. Among smokers $17 \%$ were females as compared to $66 \%$ males. On further analysis $3.3 \%$ were past smokers, $24.4 \%$ were light smokers, $10 \%$ were medium smokers and $2.3 \%$ were heavy smokers.

Among males $65.5 \%$ in rural areas as compared to $55.6 \%$ in urban areas gave history of alcohol intake. There is no intake of alcohol among females. On further analysis among males $60.3 \%$ in rural area as compared to $40.8 \%$ in urban areas take alcohol occasionally. $5.2 \%$ in rural areas as compared to $14.8 \%$ in urban areas take alcohol regularly.

TABLE - 1 Distribution of study population according to Diagnosis (ICD-10)

\begin{tabular}{|l|l|l|l|}
\hline Diagnosis & $\begin{array}{l}\text { Rural(\%) } \\
\mathbf{n}=\mathbf{6 0 0}\end{array}$ & $\begin{array}{l}\text { Urban(\%) } \\
\mathbf{n}=\mathbf{6 0 0}\end{array}$ & $\begin{array}{l}\text { Total (\%) } \\
\mathbf{n}=\mathbf{1 2 0 0}\end{array}$ \\
\hline $\begin{array}{l}\text { Infections \& parasitic diseases } \\
\begin{array}{l}\text { Endocrine nutrition \& } \\
\text { metabolic diseases }\end{array}\end{array}$ & $11(2 \%)$ & $38(6 \%)$ & $49(4 \%)$ \\
\hline Mental Behavior disorders & $1(0.16 \%)$ & $48(8 \%)$ & $69(6 \%)$ \\
\hline Disease of Nervous system & $1(0.16 \%)$ & $0(0 \%)$ & $1(0.08 \%)$ \\
\hline Disease of Eye \& Adnexa & $161(27 \%)$ & $5(1 \%)$ & $6(0.5 \%)$ \\
\hline Disease of Ear \& Mastoid & $45(8 \%)$ & $76(13 \%)$ & $237(20 \%)$ \\
\hline Disease of Circulatory system & $146(24 \%)$ & $25(4 \%)$ & $70(12 \%)$ \\
\hline Disease of Respiratory System & $26(4 \%)$ & $100(17 \%)$ & $246(21 \%)$ \\
\hline Disease of Digestive System & $12(2 \%)$ & $23(4 \%)$ & $49(4 \%)$ \\
\hline $\begin{array}{l}\text { Disease of Skin \& } \\
\text { subcutaneous tissue }\end{array}$ & $1(0.16 \%)$ & $9(2 \%)$ & $21(2 \%)$ \\
\hline $\begin{array}{l}\text { Disease of Musculoskeletal } \\
\text { System }\end{array}$ & $228(38 \%)$ & $0(0 \%)$ & $1(0.08 \%)$ \\
\hline Others & $2(0.32 \%)$ & $237(40 \%)$ & $465(39 \%)$ \\
\hline No Morbidity & $214(36 \%)$ & $1(0.16 \%)$ & $3(0.25 \%)$ \\
\hline
\end{tabular}

The distribution of study population according to Diagnosis (ICD-10) is shown in Table - 1. Among the study population $64 \%$ have morbidity and $36 \%$ have no morbidity. Diseases of Musculoskeletal System (39\%) followed by diseases of Circulatory system (21\%) and diseases of Eye and adnexa (20\%) were most commonly seen among study population. Infections \& parasitic diseases, Endocrine nutrition \& metabolic diseases were more common in urban areas. Disease of Eye \& Adnexa, Disease of Ear \& Mastoid and Disease of Circulatory system were more common in rural areas.

Elderly individuals presented with more number of symptoms in urban areas as compared to rural areas. Joint pains (41\%), defective vision (34\%), polyuria (12\%) and defective hearing (7\%) were most common presenting complaints. Fatigue, insomnia, chest pain, palpitations and memory loss were least common presenting complaints. Breathlessness and cough $(5 \%)$ in respiratory system, dizziness (9\%) in cardio vascular system and change in appetite and bowel habits $(2 \%)$ in gastro intestinal system were the most common presenting complaints in various systems. Joint pains were more common in females and in males urinary problems.

The most common history of previous illness was hypertension (12\%) and diabetes mellitus $(6 \%)$ in both rural and urban areas. The duration of treatment for the above illness ranged from one month to 20 years. The reason for not taking treatment was their economic inadequacy to buy medicines. On general examination $40 \%$ of elderly individuals presented with Anemia. 
TABLE-2. Distribution of study population according to Number of Morbidities/person

\begin{tabular}{|l|l|l|l|}
\hline $\begin{array}{l}\text { Number of morbidities } \\
\text { /person }\end{array}$ & Rural(\%) & Urban(\%) & Total(\%) \\
\hline 0 & $214(35.6 \%)$ & $219(36.5 \%)$ & $433(36 \%)$ \\
\hline 1 & $242(40.3 \%)$ & $223(37.2 \%)$ & $465(38.75 \%)$ \\
\hline 2 & $93(16 \%)$ & $122(20 \%)$ & $215(18 \%)$ \\
\hline$\geq 3$ & $51(9 \%)$ & $36(6.16 \%)$ & $87(7.25 \%)$ \\
\hline Total & $600(100 \%)$ & $600(100 \%)$ & $1200(100 \%)$ \\
\hline
\end{tabular}

Among the study population $64 \%$ have morbidity. $25 \%$ of the study population has more than one disease. $36 \%$ have no diseases in both the areas. $40.3 \%$ in rural areas as compared to $37.2 \%$ in urban areas have one disease. $16 \%$ in rural areas as compared to $20 \%$ in urban areas have two diseases. $9 \%$ in rural areas compared to $6.16 \%$ in urban areas have three and above more diseases. No. of Morbidities was found to be increased with increasing age. No. of morbidities were found to be more among females when compared to males.

\section{Discussion}

The percentage of elderly individuals in our study area ranged from $6.2 \%$ to $8.8 \%$ with an average of $6.8 \%$. Among the study population $44 \%$ (527) were in the age group $60-64$ years. $60 \%$ of the study population were females and $40 \%$ were males. Majority of the study population $75.75 \%$ were illiterates, $42 \%$ were singles, $72 \%$ of the study population had some form of social support, $22.5 \%$ were employed, (63\%) belong to class $\mathrm{V}$ and $98.9 \%$ of the study population take mixed diet.

Among the study population $64 \%$ have morbidity and $36 \%$ have no morbidity. Diseases of Musculoskeletal System (39\%) followed by diseases of Circulatory system (21\%) and diseases of Eye and adnexa (20\%) were most commonly seen among study population. Joint pains (41\%), defective vision (34\%), polyuria $(12 \%)$ and defective hearing $(7 \%)$ were most common presenting complaints. The most common history of previous illness was hypertension $(12 \%)$ and diabetes mellitus $(6 \%)$ in both rural and urban areas. $40 \%$ of elderly individuals presented with Anemia. Analysis of 200 patients attending geriatric clinics at All India institute of medical science, Delhi by Khilnani GC et al (1995) showed that 33.5\% had osteoarthritis, 31\% had hypertension $23.5 \%$ had cataract, $16.5 \%$ had coronary artery disease 14.5 had diabetes mellitus and $11.5 \%$ had depression[8]. Khokhar A et al In their study observed that dental problems were by far the commonest morbidity suffered by the subjects $(90.62 \%)$ followed by those of locomotion/joints $(71.09 \%)$, visual impairment (69\%), respiratory tract involvement (53\%) and hypertension (37.5\%) [9]. In a study done by I.C.M.R. in rural community visual impairment $(65 \%)$ was the leading morbidity followed by joint involvement $(36 \%)$, respiratory tract $(10 \%)$, skin $(8.5 \%)$, CNS $(7.45 \%)$ and CVS $(6.3 \%)[6]$. Vashist et al in a study conducted at P.H.C. Rohtak have reported commonest morbidity to be cataract $(46.22 \%)$ followed by COPD $(35.16 \%)$ and hypertension (12.45\%)[10]. Sarkar in a study conducted in an old age home at Calcutta stated the commonest morbidity to be visual loss (96\%), arthritis (57\%), cataract (51\%) and hypertension (44\%) [11]. Seby K. et al in their study found One or more physical illnesses were present in $69.8 \%$ of the subjects [12]. The most common morbidity was visual impairment, followed by cardiovascular disease, rheumatic illnesses, pulmonary illnesses, hearing impairment, genitourinary diseases and neurological disorders.

$38.75 \%$ have one disease, $18 \%$ have two diseases and $7.25 \%$ - have more than three diseases in our study. Among 1070 elderly patients coming to P.H.C. Bhopauli, Varanasi, A.K.Singh et al (1996) found that $20 \%$ have one disease, $23 \%$ - two diseases, $22 \%$ - three diseases $15 \%$ - four diseases, $12 \%$ - five diseases and $8 \%$ have more than five diseases[13]. Seby K. et al in their study found that one or more physical illnesses were present in $69.8 \%$ of the subjects [12].

The limitations of the study were detailed investigations regarding the physical illness were not done due to time and financial constraints. Studies done in Andhra Pradesh were not found during the review. Subjective bias may be encountered with difference in levels of understanding by the study population.

\section{Conclusions}

Among the study population 64\% have morbidity. Diseases of Musculoskeletal System (39\%) followed by diseases of Circulatory system (21\%) and diseases of Eye and adnexa $(20 \%)$ were most commonly seen among study population. Joint pains (41\%), defective vision (34\%), polyuria (12\%) and defective hearing (7\%) were most common presenting complaints. The most common history of previous illness was hypertension $(12 \%)$ and diabetes mellitus $(6 \%)$ in both rural and urban areas. $40 \%$ of elderly individuals presented with Anemia.

$25 \%$ of the study population has more than one disease. Most of them had chronic diseases. Hence special clinics for elderly need to be organized and integrated services should be provided in clinics dealing with geriatric population. Optional physical treatment and special attention and focus on various factors must be 
major goals in developing care programs for geriatric population. Measures to enhance social support systems and social integration like guidance, counseling to the family members and financial support to the elderly need to be provided through voluntary agencies and welfare associations. To enable and support voluntary and nongovernmental organizations to supplement the care provided by the family, with great emphasis on noninstitutional care. Health professionals need to be oriented to the needs of geriatric population at PHC or CHC. More Health insurance schemes are needed for elderly.

[1]. World Population Aging 2007. Online 2007 [Cited 2012 July 15]. Available from URL: http://www.un.org/esa/population/unpop.htm.

[2]. UN Report on Current Status of the Social Situation, Well-Being, Participation in Development and Rights of Older Persons Worldwide, Department of Economic and Social Affairs, United Nations. New York. 2011. Available from: URL: http://www.un.org/esa/socdev/ageing/ documents/publications/current-status-older-persons.pdf.

[3]. United Nations Population Fund (UNFPA) and Help Age International. Ageing in the Twenty-First Century: A Celebration and a Challenge, New York. 2012. Available from: URL: https://www.unfpa.org/public/home/ publications/pid/11584.

[4]. Dr. Indira Jai Prakash "Ageing in India" World health organization 1999.

[5]. World Health Organization. World Health Day - 7 April 2012; Theme: Ageing and health: Good health adds life to years. WHO. Available from: URL:http://www.who.int/world-health-day/en/

[6]. VAHI (1997), Report of the Independent Commission on Health in India, Chapter 14, Health Problems of Specialized Groups.

[7]. WHO (1993), International Statistical Classification of Diseases and Related Health Problems, Tenth Revision, Vol 2.

[8]. Khilnani GC, Dey AB, Nagarkar KM "Symptom Analysis of geriatric out patients" Journal of Association of physicians of India 1995; Vol. 43 (12) P 885.

[9]. Khokhar A, Mehra M. Life style and morbidity profile of geriatric population in an urbans community of Delhi. Indian J Med Sci 2001;55:609-15

[10]. Vashisht B.M. Morbidity among elderly at PHC, (Chin district) Rohtale, 1996. 26th Annual Conference of IAPSM, Surat, 1999.

[11]. Sarka N. "A study of morbidity profile of aged people 60 years and above in old age home at Calcutta" 1994-1995 at the Joint Conference of IPHA, 10-12th March 2000.

[12]. K. Seby, Suprakash Chaudhury, and Rudraprosad Chakraborty, Prevalence of psychiatric and physical morbidity in an urban geriatric population. Indian J Psychiatry. 2011 Apr-Jun; 53(2): 121-127.

[13]. Singh.A. K, Manju Singh, D. S. Singh "Health problems in rural Elderly at Varnasi, Uttar Pradesh" JAPI 1996, 44 (8):540-543. 